Int. J. Electrochem. Sci., 12 (2017) 10687 - 10700

\title{
Heteroatom-enhanced the Formation of Mesoporous Carbon Microspheres with High Surface Area as Supercapacitor Electrode Materials
}

\author{
Zhuan Gao ${ }^{1}$, Xiaobin Huang ${ }^{2, *}$, Kuiyong,Chen ${ }^{2}$, Chaoying Wan ${ }^{3}$, Hong Liu $^{2}$ \\ ${ }^{1}$ School of Chemistry and Chemical Engineering, Shanghai Jiao Tong University, Shanghai, China, \\ 200240 \\ ${ }^{2}$ School of Aeronautics and Astronautics, Shanghai Jiao Tong University, Shanghai, China, 200240 \\ ${ }^{3}$ International Institute for Nanocomposites Manufacturing (IINM), WMG, University of Warwick, \\ UK, CV4 7AL \\ *E-mail: xbhuang@ @jtu.edu.cn
}

doi: $10.20964 / 2017.11 .55$

Received: 23 May 2017 / Accepted: 6 September 2017 / Published: 12 October 2017

\begin{abstract}
A novel supercapacitor electrode material based on heteroatom (N, O, P) doped mesoporous carbon microspheres (HMCMSs) was produced via a carbonization of highly cross-linked polyphosphazene microspheres (PMSs), with $\mathrm{N}, \mathrm{O}, \mathrm{P}$ acting as high efficient pore-forming agent. PMSs were synthesized through the polymerization reaction between melamine (MA) and hexachlorocyclotriphosphazene (HCCP). The high level of heteroatom atom of PMSs effectively afforde HMCMSs with high specific surface area $\left(1854.1 \mathrm{~m}^{2} / \mathrm{g}\right)$, united mesopore structure (pore width $\sim 3 \mathrm{~nm}$ ), as well as high supercapacitor performance. HMCMSs based electrodes exhibited highest specific capacitance of $274 \mathrm{~F} / \mathrm{g}$ in $6 \mathrm{M} \mathrm{KOH}$ aqueous electrolyte at a current density of $0.2 \mathrm{~A} / \mathrm{g}$, and excellent cycling durability which had $98.4 \%$ capacitance retained even after 2000 cycles. These animative consequences of HMCMSs based electrodes show them great potential in developing highperformance supercapacitors for actual application.
\end{abstract}

Keywords: Heteroatom-doped; Mesoporous carbon; Polyphosphazene; Supercapacitor

\section{$\underline{\text { FULL TEXT }}$}

(C) 2017 The Authors. Published by ESG (www.electrochemsci.org). This article is an open access article distributed under the terms and conditions of the Creative Commons Attribution license (http://creativecommons.org/licenses/by/4.0/). 